\title{
Treatment-Resistant Depression: Managed Care Considerations
}

\author{
John G. Tierney II, MD
}

\begin{abstract}
BACKGROUND: Treatment-resistant depression (TRD) presents a unique challenge in managed care, requiring review of both the clinical and economic components of care.

OBJECTIVE: To review the TRD disease state as well as data supporting the various therapeutic options available for the treatment of persistent depression in managed care.

SUMMARY: While there is no consensus on the definition of TRD, persistent disease can generally be defined as depression that fails to respond to adequate treatment. When initial treatment is not effective or tolerable after 6 to 8 weeks of therapy, the American Psychiatric Association (APA) treatment guidelines recommend dose titration, augmentation, or switching. In the case of a therapy switch, the body of evidence suggests that selection of an agent with a different mechanism of action than the initial agent may be the most effective treatment. Furthermore, when patients maintain continuous therapy for the recommended treatment duration, outcomes are improved compared with patients who discontinue therapy early. As a result, the most effective treatment strategies promote improved patient compliance as well as the use of agents associated with a reduced incidence of premature discontinuation and therapy change early in the treatment program. While data supporting these clinically effective components of therapy exist, few data are available demonstrating the most cost-effective therapeutic options for TRD.
\end{abstract}

CONCLUSION: This analysis suggests that managed care providers could benefit from a model that they can customize to evaluate the overall costeffectiveness of different strategies in the management of depression.

KEYWORDS: Treatment-resistant, Depression, Economic model, Switch, SSRI, SNRI, Venlafaxine extended release (XR), Managed care, Cost-effectiveness

J Manag Care Pharm. 2007;13(6)(suppl S-a):S2-S7

Copyright@ 2007, Academy of Managed Care Pharmacy. All rights reserved.

\section{Author}

JOHN G. TIERNEY II, MD, is in private practice in general adult and geriatric psychiatry and is a clinical associate professor of psychiatry, University of Texas Health Science Center Medical School, San Antonio.

AUTHOR CORRESPONDENCE: John G. Tierney II, MD, Clinical Associate Professor, University of Texas Health Science Center at San Antonio, 1202 East Sonterra Blvd., Suite 202, San Antonio, TX 78258. Tel: (210) 615-8458; Fax: (210) 615-6966;

E-mail: jgtierney@swnp.xohost.com
$\mathrm{M}$ ajor depressive disorder (MDD) is the second most common psychiatric disorder in the United States. ${ }^{1}$ The lifetime prevalence for major depression appears to be between $6 \%$ and $16 \% .^{2,3}$ While the etiology of depression is not fully understood, evidence suggests that depression is the result of a complex interaction among biological, genetic, psychosocial, and environmental factors. ${ }^{4,5}$

The Diagnostic and Statistical Manual, Fourth Edition, Text Revision (DSM-IV-TR) outlines common signs and symptoms of a major depressive episode. ${ }^{6}$ While not a definitive list, the following signs and symptoms are derived from DSM-IV-TR criteria:

1. Loss of interest, satisfaction, or pleasure in almost all activities, lasting at least 2 weeks

2. Appetite and sleep disturbance (early morning awakening is "classic")

3. Decreased energy, concentration, or libido

4. Low self-esteem or excessive guilt

5. Recurrent thoughts of death or suicide

6. Psychomotor agitation or retardation

7. Occasional psychotic features (delusions, hallucinations)

8. Atypical features may be present in elderly, children/ adolescents

The risk of depression may be related to the same combination of factors that produce depression. ${ }^{5}$ The highest rates of depression occur in individuals between the ages of 25 and 44 years. Females are almost twice as likely (10\%-25\%) as males (5\%-12\%) to experience depression. Genetic predisposition appears to be a significant risk factor. Individuals with firstgeneration relatives with major depression have a 1.5 to 3 times greater chance of experiencing depression compared with individuals without a similar family history. ${ }^{4,7}$ Individuals who have been victims of trauma or abuse are also at increased risk of depression. ${ }^{8,9}$ In addition to the risk factors described, some medications can cause depression-like symptoms, including sedatives, narcotics, and pain relievers. ${ }^{10}$

Untreated depression has significant economic, social, physical, and psychological consequences. Several factors contribute to the economic burden of depression, including the prevalence of the disease, treatment rate, and rate and degree of impairment. ${ }^{11}$ Studies conducted in 1990 estimated that depressed workers in the United States lost an average of 5.6 productive hours per week. The same studies estimated that depression-related costs of direct treatment, lost earnings, and indirect workplace costs translated into an economic burden of between $\$ 44$ and $\$ 53$ billion per year. These estimates did not include labor costs associated with short- and long-term disability. ${ }^{12,13}$ Between 1990 and 2000, the total economic burden of depression remained relatively stable. While treatment rates increased substantially over that period, indirect workplace 


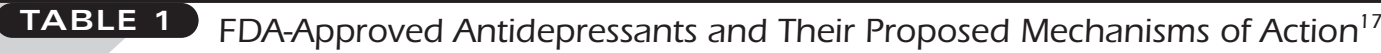

\begin{tabular}{l|l}
\hline Class/Drugs & \multicolumn{1}{c}{ Proposed Mechanism of Action } \\
\hline $\begin{array}{l}\text { Tricyclic antidepressants (TCAs) } \\
\text { (e.g, .amitriptyline, nortriptyline, imipramine, desipramine) }\end{array}$ & Nonselectively inhibits serotonin, dopamine, and norepinephrine reuptake \\
\hline $\begin{array}{l}\text { Monoamine oxidase inhibitors (MAOIs) nonselective } \\
\text { (e.g., phenelzine, tranylcypromine, isocarboxazid; selegeline [transdermal } \\
\text { delivery system]) }\end{array}$ & $\begin{array}{l}\text { Inhibit enzymes (MAO-A, MAO-B) involved in the breakdown of serotonin, } \\
\text { norepinephrine, and dopamine }\end{array}$ \\
\hline $\begin{array}{l}\text { Selective serotonin reuptake inhibitors (SSRIs) } \\
\text { (e.g., fluoxetine, paroxetine, fluvoxamine, sertraline, citalopram, escitalopram) }\end{array}$ & $\begin{array}{l}\text { Selectively inhibit serotonin reuptake; have some effects on other } \\
\text { neurotransmitters }\end{array}$ \\
\hline $\begin{array}{l}\text { Norepinephrine and dopamine reuptake inhibitor } \\
\text { (e.g., bupropion) }\end{array}$ & Inhibits norepinephrine and dopamine reuptake \\
\hline $\begin{array}{l}\text { Serotonin antagonist reuptake inhibitors } \\
\text { (e.g., trazodone, nefazodone) }\end{array}$ & $\begin{array}{l}\text { Primarily antagonize 5-HT2 receptors; nefazodone also modestly inhibits } \\
\text { serotonin, norepinephrine, and dopamine reuptake }\end{array}$ \\
\hline $\begin{array}{l}\text { Noradrenergic and specific serotonergic agent } \\
\text { (e.g., mirtazapine) }\end{array}$ & $\begin{array}{l}\text { Antagonizes alpha2 autoreceptors and heteroreceptors; blocks 5-HT2A/C and } \\
\text { 5-HT3 receptors; stimulates 5-HTl receptors }\end{array}$ \\
\hline $\begin{array}{l}\text { Serotonin-norepinephrine reuptake inhibitors (SNRIs) } \\
\text { (e.g., venlafaxine, duloxetine) }\end{array}$ & Inhibit serotonin and norepinephrine reuptake \\
\hline
\end{tabular}

FDA $=$ U.S. Food and Drug Administration

costs remained the largest single cost component. ${ }^{11}$ The characteristics of depression, including fatigue, reduced concentration, and difficulty performing routine tasks, all contribute to reduced productivity and increased absenteeism. ${ }^{11}$

Patients with depression also have increased medical morbidity and mortality, including higher rates of premature death related to cardiovascular disease and myocardial infarction. ${ }^{14,15}$ In addition, $15 \%$ of people diagnosed with major depression will commit suicide, and two thirds of all suicides are related to depression. ${ }^{16}$

\section{Treatment Options}

Seven different pharmacologic classes of medications can be used to treat depression (Table 1). ${ }^{17}$ The primary targets of most major antidepressant drug classes are the neurotransmitters serotonin and norepinephrine. The oldest agents are the tricyclic antidepressants (TCAs) and monoamine oxidase inhibitors (MAOIs). TCAs inhibit the reuptake of serotonin and norepinephrine. MAOIs block the activity of enzymes (MAO-A, MAO-B) that are involved with the breakdown of serotonin, norepinephrine, and dopamine. Although both TCAs and MAOIs are effective, their use is limited, primarily because of side effects. TCAs are associated with cardiac, anticholinergic, and hypotensive side effects, as well as the potential for severe toxicity with overdose. Oral MAOIs require adherence to dietary restrictions, except for the newer transdermal systems at entry-level dosages. Newer agents are as effective as TCAs and MAOIs but have been shown to be safer and more tolerable. ${ }^{17}$

Among the newer antidepressant agents, selective serotonin reuptake inhibitors (SSRIs) and serotonin and norepinephrine reuptake inhibitors (SNRIs) have been commonly used. Studies have shown that SSRIs and SNRIs are effective for MDD when patients remain on therapy at the minimum recommended dose and duration of time set forth in clinical practice guidelines (at least 4-9 continuous months). ${ }^{18-20}$ Although many antidepressants have similar efficacy as first-line agents, few studies have compared them as second-line treatments following initial treatment failure. ${ }^{21}$

\section{Treatment Issues}

In the managed care environment, initial and subsequent treatment efficacy, tolerability, and adherence influence clinical outcomes and pharmacoeconomic aspects of care. In the treatment of depression, outcomes of particular concern that are affected by these factors include rates of response and remission. While a response is defined by a partial improvement in depressive symptoms, remission is characterized by a full recovery from depressive symptoms and a return to normal functioning. ${ }^{22}$ Measures of economic burden (probability of paid employment, time lost from work, and total health care costs) correlate significantly to these clinical outcomes. ${ }^{23}$ In a study of 290 primary care patients with MDD, patients who achieved remission at 12 months had a 16\% higher probability of paid employment and missed 10 fewer days of work per year compared with patients with persistent depression (mean, 16.8 days). ${ }^{23}$ At year 2, patients who achieved remission had $49 \%$ lower total health care costs compared with those with persistent depression after adjusting for baseline costs and 
other covariates. ${ }^{23}$ It should be noted, however, that only 1 of the economic endpoints in this study reached statistical significance.

Even when an agent is effective, lack of compliance can be a major barrier to successful treatment. The ability of the patient to tolerate a drug's side effects strongly influences their compliance with therapy. Developing effective pharmacotherapy strategies that improve adherence and increase remission rates can potentially lower costs, reduce the risk of relapse, and improve psychosocial functioning and productivity. ${ }^{24,25}$

\section{- Treatment-Resistant Depression}

While there is no consensus on the definition of treatmentresistant depression (TRD), certain guidelines based on accepted clinical outcomes measures, such as the Hamilton Rating Scale for Depression (HAM-D), can be used to identify TRD. Importantly, most published definitions of TRD imply that the patient has had either no response or inadequate response to adequate treatment. Nierenberg and DeCecco suggested that TRD in patients who received adequate treatment could be defined based on any of 3 criteria: failure to achieve a minimum response (e.g., less than a 25\% decrease from baseline HAM-D score), failure to achieve a response (e.g., less than a 50\% decrease from baseline HAM-D score), or failure to achieve remission (e.g., a final HAM-D score of at least 7). ${ }^{26}$

Patients who are treatment resistant use a disproportionately larger share of health care resources, have significantly more claims for comorbid conditions, and cost employers more in lost productivity compared with patients with major depression who respond to treatment. ${ }^{27}$

Many depressed patients fail to achieve a response or remission after being placed on initial therapy with an SSRI. Second-line pharmacologic treatment options include titrating the dose of the initial antidepressant, augmenting therapy with a second agent, or switching to another SSRI or an agent with a different mechanism of action, such as an SNRI. ${ }^{28-31}$ The ARGOS study evaluated an SNRI, venlafaxine extended release XR, in patients who had failed to respond to or could not tolerate conventional antidepressants, primarily SSRIs, in a psychiatric outpatient setting. Those treated with venlafaxine XR had significantly higher remission rates (59.3\%) at 24 weeks compared with those treated with conventional antidepressants (i.e., paroxetine, citalopram, sertraline, fluoxetine, mirtazapine, or other treatments) $(51.5 \% ; P<0.001){ }^{21}$

Recent results from the Sequenced Treatment Alternatives to Relieve Depression (STAR*D) study showed that among patients who did not achieve remission with initial therapy, approximately one third achieved remission by augmentation with a second agent and about one fourth achieved remission by switching to a different antidepressant. ${ }^{32}$ Current American Psychiatric Association (APA) practice guidelines suggest that if at least moderate improvement is not observed following 6 to 8 weeks of initial pharmacotherapy, the treatment regimen should be reevaluated..$^{33}$

\section{Managed Care Strategies} to Improve Depression Treatment Outcomes

When depressed patients maintain continuous therapy for the recommended treatment duration, health care resource costs are reduced compared with patients who discontinue therapy early. ${ }^{20,34}$ It then follows that overall costs should decrease when patient compliance is improved and agents associated with a reduced incidence of early discontinuation and therapy change are utilized early in the treatment program. ${ }^{35}$ Managed care organizations (MCOs) are challenged to identify optimal, cost-effective strategies for the treatment of depression and improve patient adherence to antidepressant therapy. ${ }^{36}$

MCOs have a limited role in direct patient care; therefore, they must be creative in developing programs or identifying treatment strategies that have the potential to influence patient adherence. Compared with standard care models, patient support programs (collaborative care model) that educate patients about the value of medication adherence, increase awareness of potential adverse events associated with antidepressant medications, and provide follow-up to ensure continued compliance were found to improve efficacy in the treatment of depression. ${ }^{37-40}$ Mail-based educational intervention has also been shown to positively impact patient adherence to therapy. ${ }^{36}$

When initial treatment is not effective or tolerable, APA treatment guidelines recommend that the clinician should consider treatment with another agent. While there is not a solid body of data to guide clinicians in decisions concerning secondline treatment options, the STAR*D trial evaluated 4 levels of treatment in patients who had not responded adequately to an initial standard antidepressant trial: level 1 (identify treatment-resistant patients), level 2 (switch and/or augment antidepressants), level 3 (switch to an agent with a different mechanism of action), and level 4 (treat with either an MAOI or venlafaxine XR plus mirtazapine). ${ }^{32,41-43}$ The trial results may help to define which subsequent treatment strategies, in what sequence, and in what combination(s) produce the best clinical results with the least side effects.

Data on switching and related resource utilization in managed care patients are limited. However, some evidence exists that an earlier switch (before 6 weeks of initial treatment) to an agent with an alternative mechanism of action may prevent unnecessary cycling. ${ }^{44}$

Direct medical costs associated with switching antidepressants were recently reported in a poster presented at the Academy of Managed Care Pharmacy Educational Conference, October 5-8, 2006. Analysis of data from a national database (PharMetrics) of medical and pharmacy claims suggested that, overall, costs declined when patients switched antidepressant 


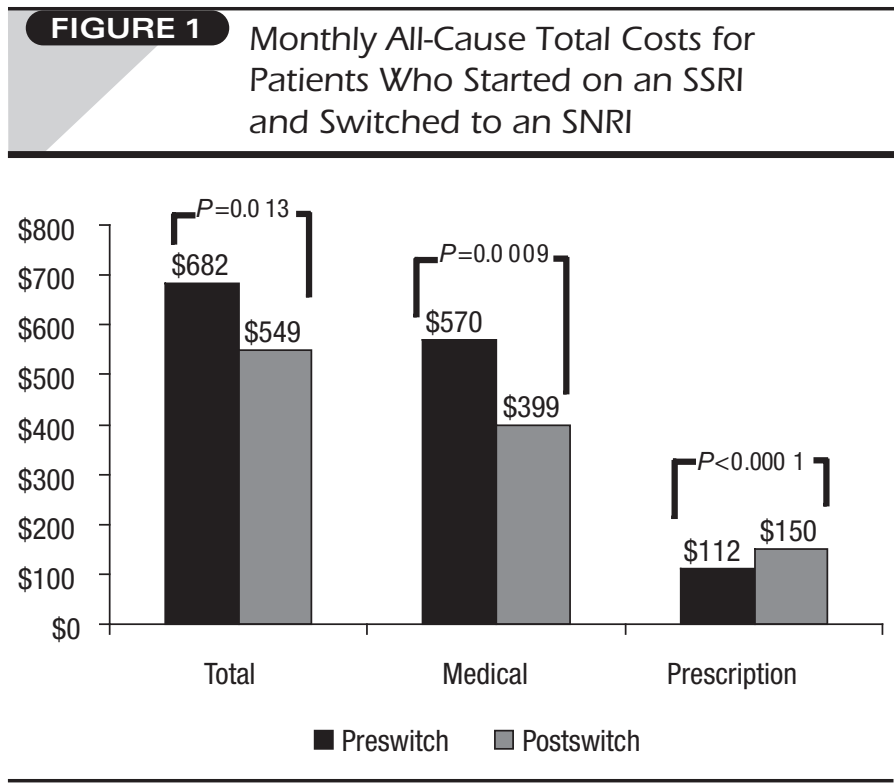

SNRI=serotonin and norepinephrine reuptake inhibitors. $S S R I=$ selective serotonin reuptake inhibitors.

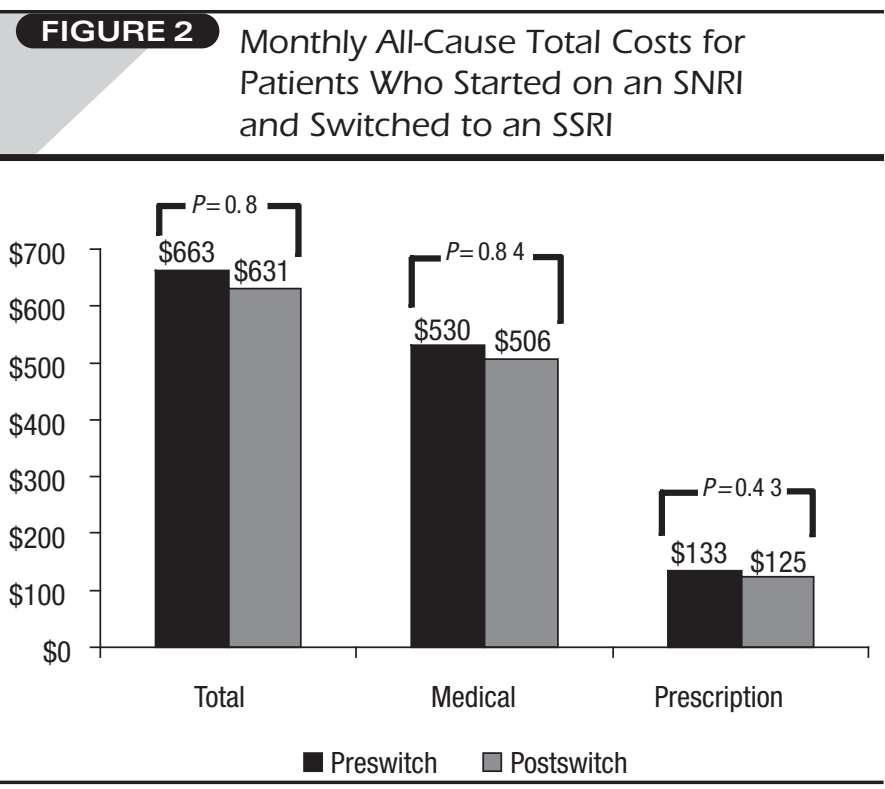

SNRI=serotonin and norepinephrine reuptake inhibitors. SSRI=selective serotonin reuptake inhibitors. classes. Greater cost reductions due to reduced medical costs were realized when patients switched to an SNRI (venlafaxine) from an SSRI (citalopram, fluoxetine, paroxetine, sertraline) compared with switching to an SSRI from an SNRI (Figures 1 and 2).$^{44}$ In addition, higher costs were associated with patients who switched among multiple SSRIs before switching to an SNRI. ${ }^{44}$ However, it is important to note that these findings may have been influenced by differences in the baseline characteristics of the patients involved.

Recently, an economic model was developed to explore the results of using generic SSRIs, such as escitalopram, paroxetine controlled release, sertraline, and venlafaxine XR as second-line agents for the treatment of unresolved depression following a treatment failure. Efficacy parameters used to develop the model were derived from clinical trial results based on the HAM-D and Montgomery-Asberg Depression Rating Scale (MADRS). ${ }^{45,46}$ While managed care experts express a preference for the self-administered Patient Health Questionnaire. ${ }^{47}$ or the Quality Improvement of Depression Scale $)^{48}$ as evaluation tools, clinical studies do not use those instruments to evaluate primary endpoints, hence the reliance on HAM-D and MADRS scores in the model.

The economic model, which was constructed in Microsoft Excel, is a budget-impact and decision analysis tool that allows the user to input managed care-specific information. Results of the analyses and a full description of the model are addressed in the next article of this publication.

\section{Conclusion}

When patients with depression fail initial therapy, the result is often increased costs to health plans and a poorer quality of life for patients. Because no clear data support the use of one agent over another as second-line therapy in patients with TRD, managed care providers could benefit from a model that they can customize with their own variables, such as acquisition costs and outcome parameters, to evaluate the overall costeffectiveness of different strategies.

\section{ACKNOWLEDGMENTS}

The author would like to acknowledge Wendy Gloffke, PhD, medical writer, and the staff writer, Communications Impact, LLC, for their assistance with this article.

\section{DISCLOSURES}

The author serves as a consultant and/or on the speakers bureau for Wyeth Pharmaceuticals Inc., Cephalon, and Bristol-Myers Squibb. He received an honorarium for his participation in this study.

\section{REFERENCES}

1. Kessler RC, McGonagle KA, Zhao S, et al. Lifetime and 12-month prevalence of DSM-III-R psychiatric disorders in the United States. Results from the National Comorbidity Survey. Arch Gen Psychiatry. 1994;51:8-19.

2. Kessler RC, Berflund P, Demler O, et al. The epidemiology of major depressive disorder. Results from the national comorbidity replication (NCS-R). JAMA. 2003;289:3095-3105.

3. Murphy JM, Laird NM, Monson RR, et al. A 40-year perspective on the prevalence of depression: the Stirling County Study. Arch Gen Psychiatry. 2000;57:209-15. 
4. U.S. Dept. of Health and Human Services. Mental health: a report of the surgeon general. Rockville, MD: U.S. Dept. of Health and Human Services, Substance Abuse and Mental Health Services Administration, Center for Mental Health Services, National Institutes of Health, National Institute of Mental Health; 1999. Available at: http://www.surgeongeneral.gov/library/ mentalhealth/chapter4/sec3_1.html. Accessed February 27, 2007.

5. National Institute of Mental Health. Depression. Available at: http://www. nimh.nih.gov/publicat/depression.cfm\#ptdepl. Accessed June 16, 2006.

6. American Psychiatric Association. Diagnostic and Statistical Manual of Mental Disorders. 4th ed., text revision (DSM-IV-TR). Washington, DC: American Psychiatric Association; 2000:356-57.

7. Bland RC. Epidemiology of affective disorders: a review. Can J Psychiatry. 1997;142:367-77.

8. Bruce SE, Weisberg RB, Dolan RT, et al. Trauma and posttraumatic stress disorder in primary care patients. Primary Care Companion. J Clin Psychiatry. 2001;3(5):211-17.

9. Molnar BE, Buka SL, Kessler RC. Child sexual abuse and subsequent psychopathology: results from the National Comorbidity Survey. Am J Public Health. 2001;91:753-60.

10. Cheong J, Herkov M, Goodman W. Risk factors associated with depression. Available at: http://psychcentral.com/library/depression_risk.htm. Accessed June 12, 2006.

11. Greenberg PE, Kessler RC, Birnbaum HG, et al. The economic burden of depression in the United States: how did it change between 1990 and 2000? J Clin Psychiatry. 2003;64:1465-75.

12. Stewart WF, Ricci JA, Chee E, et al. Cost of lost productive work time among US workers with depression. JAMA. 2003;289:3135-44.

13. Greenberg PE, Stiglin LE, Finkelstein SN, et al. The economic burden of depression in 1990. J Clin Psychiatry. 1993;54:405-18.

14. Pratt LA, Ford DE, Crum RM, et al. Depression, psychotropic medication, and risk of myocardial infarction. Circulation. 1996;94:3123-29.

15. Musselman DL, Evans DL, Nemeroff CB. The relationship of depression to cardiovascular disease. Arch Gen Psychiatry. 1998;55:580-92.

16. Bostwick JM, Pankratz VS. Affective disorder and suicide risk: a reexamination. Am J Psychiatry. 2000;157:1925-32.

17. Pies R. Handbook of Essential Psychopharmacology. 2nd ed. Washington, DC: American Psychiatric Press Institute; 2005:19-138.

18. Geddes JR, Carney SM, Davies C, et al. Relapse prevention with antidepressant drug treatment in depressive disorders: a systematic review. Lancet. 2003;361:653-61

19. Claxton AJ, Li Z, McKendrick J. Selective serotonin reuptake inhibitor treatment in the UK: risk of relapse or recurrence of depression. Br J Psychiatry. 2000; 177:163-68

20. Eaddy MT, Druss BG, Sarnes MW, et al. Relationship of total health care charges to selective serotonin reuptake inhibitor utilization patterns including the length of antidepressant therapy — results from a managed care administrative claims database. J Manag Care Pharm. 2005;11(2):145-50. Available at: http://www.amcp.org/data/jmcp/Original\%20Research-145-150.pdf. Accessed February 27, 2007

21. Baldomero EB, Ubago JG, Cercós CL, et al. Venlafaxine extended release versus conventional antidepressants in the remission of depressive disorders after previous antidepressant failure: ARGOS Study. Depress Anxiety. 2005; 22:68-76
22. Kupfer DJ. Long-term treatment of depression. J Clin Psychiatry. 1991;52 (suppl 5):28-34.

23. Simon GE, Revicki D, Heiligenstein J, et al. Recovery from depression, work productivity, and health care costs among primary care patients. Gen Hosp Psychiatry. 2000;22:153-62.

24. Judd LL, Paulus MJ, Schettler PJ, et al. Does incomplete recovery from first lifetime major depressive episode herald a chronic course of the illness? Am J Psychiatry. 2000;157:1501-04.

25. Nierenberg AA, Wright EC. Evolution of remission as a new standard in the treatment of depression. J Clin Psychiatry. 1999;60:7-11.

26. Nierenberg AA, DeCecco L. Definitions of antidepressant treatment response, remission, nonresponse, partial response, and other relevant outcomes: a focus on treatment-resistant depression. J Clin Psychiatry. 2001;62(suppl 16):5-9.

27. Greenberg P, Corey-Lisle PK, Birnbaum H, et al. Economic implications of treatment-resistant depression among employees. Pharmacoeconomics. 2004;22(6):363-73.

28. Souery D, Amsterdam J, de Montigny C, et al. Treatment resistant depression: methodological overview and operational criteria. Eur Neuropsychopharmacol. 1999;9(1-2):83-91.

29. Thase ME, Rush AJ. Treatment resistant depression. In: Bloom PE, Kupfer DJ, eds. Psychopharmacology: The Fourth Generation of Progress. New York, NY: Raven Press, Ltd.; 1995:1081-97.

30. O'Reardon AA, Amsterdam JD. Treatment-resistant depression: progress and limitations. Psychiatr Ann. 1998;28(11):633-40.

31. American Psychiatric Association. Practice Guidelines for the Treatment of Patients with Major Depressive Disorder. 2nd ed. Arlington, VA: American Psychiatric Association; 2000

32. Rush AJ, Trivedi MH, Wisniewski SR, et al. Bupropion-SR, sertraline, or venlafaxine-XR after failure of SSRIs for depression. N Engl J Med. 2006; 354(12):1231-42.

33. American Psychiatric Association. Treatment recommendations for patients with major depressive disorder. Available at: http://www.psych.org/psych_ pract/treatg/pg/Depression2e.book-7.cfm. Accessed June 16, 2006.

34. Thompson D, Buesching D, Gregor KJ, Oster G. Patterns of antidepressant use and their relation to cost of care. Am J Manag Care. 1996;2:1239-46.

35. Sheehan DV, Eaddy MT, Shah MB, Mauch RP. Differences in total medical costs across the SSRIs for the treatment of depression and anxiety. Am J Manag Care. 2005;11:S354-61.

36. Hoffman L, Enders J, Luo J, et al. Impact of an antidepressant management program on medication adherence. Am J Manag Care. 2002;9:70-80.

37. Katon W, Von Korff M, Lin E, et al. Collaborative management to achieve treatment guidelines. Impact on depression in primary care. JAMA. 1995;273(13):1026-31.

38. Hunkeler EM, Meresman JF, Hargreaves WA, et al. Efficacy of nurse telehealth care and peer support in augmenting treatment of depression in primary care. Arch Fam Med. 2000;9(8):700-08.

39. Simon GE, Ludman EJ, Tutty S, et al. Telephone psychotherapy and telephone care management for primary care patients starting antidepressant treatment: a randomized controlled trial. JAMA. 2004;292(8):935-42.

40. Trivedi MH, Rush AJ, Wisniewski SR, et al. Evaluation of outcomes with citalopram for depression using measurement-based care in STAR*D: implications for clinical practice. Am J Psychiatry. 2006;163:28-40. 
41. Fava M, Rush AJ, Wisniewski SR, et al. A comparison of mirtazapine and nortriptyline following two consecutive failed medication treatments for depressed outpatients: a STAR*D report. Am J Psychiatry. 2006;163:1161-72.

42. Trivedi MH, Fava M, Wisniewski SR, et al. Medication augmentation after the failure of SSRIs for depression. N Engl J Med. 2006;354(12):1243-52.

43. Thase ME, Blomgren SL, Birkett MA, et al. Fluoxetine treatment of patients with major depressive disorder who failed initial treatment with sertraline.

J Clin Psychiatry. 1997;58:16-21.

44. Kruzikas D, Khandher RK, McLaughlin T, Tedesch M. Patterns of antidepressant use and cost implications of product switching. Poster presented at: Academy of Managed Care Pharmacy Educational Conference; October 5-8, 2006; Nashville, TN.
45. Hamilton M. A rating scale for depression. J Neurol Neurosurg Psychiatry. 1960;23:56-62.

46. Montgomery SA, Asberg M. A new depression scale designed to be sensitive to change. Br J Psychiatry. 1979;134:382-89.

47. Kroenke K, Spitzer RL. The PHQ-9: a new depression and diagnostic severity measure. Psychiatric Ann. 2002;32:509-21.

48. Rush AJ, Trivedi MH, Ibrahim HM, et al. The 16-item Quick Inventory of Depression Symptomatology (QIDS), Clinician Rating (QU+IDS-C), and Self-Report (QIDS-SR): a psychometric evaluation in patients with chronic major depression. Biol Psychiatry. 2003;54:573-83. 